\title{
A methodological approach to manipulation of hunger and thirst drive stimuli in the rat
}

\author{
PEGGY A. KEILMAN* \\ Louisiana State University in New Orleans, New Orleans, Louisiana 70122
}

The hunger and thirst drives of rats were equated using a titration procedure in a modified T-maze with food as the reinforcer on the left and water on the right. The conditions (amount) rather than schedules (hours) of maintenance were varied from day to day during a 9-day cycle which was then replicated. The results showed that condition manipulations produce reliable and approximately linear functions for individual Ss on the following response measures: percent water choices, median latencies, and body weight. Results were discussed in terms of the animals responding to the drive stimuli and also in terms of some of the methodological problems that this procedure solved. Finally, it was suggested that the construct drive as defined by conditions of maintenance might possess more utility as an experimental variable.

"Drive" has been an important aspect of theoretical interpretations of learning at least since Tolman (1932) drew the critical distinction between learning and performance. Emphasis has been placed on the energizing role of drive as reflected in Hull's (1943) formal assumption that drive multiplies habit strength to determine excitatory potential and hence performance. However, the role of drive in guiding behavior is also recognized, most formally in Hull's postulation of a characteristic drive stimulus for each drive which varies directly with the strength of that drive. But there are several methodological considerations that complicate the experimental analysis of these formal assumptions.

One problem concerns the concep1 of irrelevant drive, namely one that is not appropriate for the goal object of a response. Hull explicitly assumed that an irrelevant drive combines with the relevant drive to determine the total effective drive strength. However, if the organism is in a situation providing a choice between two commodities such as food and water, then neither drive is inherently irrelevant. Presumably, the stronger drive will determine choice and hence be viewed as the relevant drive. This situation may provide a stronger test of Hull's assumptions of drive stimuli than when the weaker drive is totally irrelevant. Also, if the stronger drive in a choice situation totally determines behavior, then the weaker drives in the same situation have no effective guiding properties in their drive stimuli.

*This report is based on part of a doctoral dissertation submitted to the University of New Mexico. The author is greatly indebted to Frank A. Logan, dissertation adviser, and to $G$. Robert Grice, Douglas P. Ferraro, and David W. Bessemer, who were members of the dissertation committee.
It would appear that a more analytic method for the measurement and control of drive is necessary as a base for further systematic analysis. The distinction between schedules and conditions of events previously made by Logan and Ferraro (1970) will be used throughout this paper. In general, conditions refer to which event occurred and give its descriptive properties. A schedule refers to when the event occurs. We may assume that drive depends on both the schedule and condition of maintenance; specifically, hunger depends on the time since last feeding, the amount given, and the residual effect of prior deprivations as reflected in body weight. The relative strength of any one drive is assumed to depend on the schedule and condition of maintenance of other commodities, specifically the dependence of hunger on the prevailing level of thirst.

A more practical problem concerns the manner of manipulating or controlling an organism's drive state. Perhaps the most common method is to control the maintenance schedule and then specify drive in terms of hours of deprivation. It should be apparent that the maintenance conditions (specifically, the amount and quality of the commodity given) are equally important, and that the time of deprivation may implicate the types of activities in which the organism engages during that time. But more important is the fact that the different levels of drive cannot be produced without simultaneously confounding changes in the time of feeding or time of running with changes in drive.

There are two other closely related methods of controlling drive: providing a measured amount of food daily or maintaining the animal at a fixed percentage of his ad lib body weight. In both cases, relatively constant levels of intake and body weight are achieved and differ primarily in which of these two factors are equated across Ss. These methods raise complications also. Long-range effects on the physical state of the organism may be confounded with their momentary drive state. Clearly, body weight alone does not specify the nature of the drive, especially if several drives are involved simultaneously. It would be advantageous to have at least two drives equated in strength.

Another practical problem is the amount of time necessary for an animal to adjust to a 23-h cyclical schedule. Reid and Finger (1955) found that 15 days were necessary for an animal to adjust to this schedule with food deprivation; Fallon (1965) found that it took 4 days for water.

The research cited here attempts to avoid some of the confounding problems by manipulating the conditions (amount) of maintenance rather than the usual schedules (hours) around a titrated $50 \%$ choice-point for each animal.

\section{METHOD \\ Subjects}

Six male hooded rats bred in the colony maintained by the Department of Psychology at the University of New Mexico were used. The rats were approximately 200 days old at the beginning of training. All animals were handled, adapted to the experimental apparatus, and magazine trained prior to the beginning of the experiment. Each rat was housed in an individual cage throughout the duration of all experimental manipulations.

\section{Apparatus}

A $3 \times 6$ in. startbox door was manually opened to provide access to an 8-ft modified T-maze. Each alley of the maze was 4 in. wide with a metal floor and a clear Plexiglas top. The sides of each alley were of two panels of Plexiglas. The left alley had black paper inserted between the sheets of Plexiglas and a black floor, while the right alley was white. The entire maze was encased in a $4 \times 4 \times 12 \mathrm{ft}$ sheet metal enclosure providing ventilation and indirect illumination from below. The top of the maze was covered with four blue Plexiglas panels that were each $3 \times 4 \mathrm{ft}$. Food was delivered through a Davis feeder into a brass cup at the end of the black alley after an animal broke a photobeam in the foodcup. Water was delivered through a solenoid valve in the right white alley after breaking the brass water cup photobeam. A guillotine door positioned $2 \mathrm{ft}$ from the goalbox in each alley contained the $S$ until he was removed by the $E$. A time measure was obtained photoelectrically for each animal from the startbox door to the 
Table 1

Titrated Values that Produced Intermediate Levels of Water Choices for Each $\mathbf{S}$

\begin{tabular}{ccccccc}
\hline & \multicolumn{2}{c}{ Amount Given } & & \multicolumn{2}{c}{ Percent Water Responses } \\
\cline { 2 - 6 } S & Food (g) & Water (cc) & & 1 & 2 & 3 \\
\hline 1 & 9 & 15 & 10 & 20 & 10 \\
2 & 11 & 13 & 30 & 20 & 50 \\
3 & 11.5 & 12.5 & 50 & 50 & 20 \\
7 & 11 & 13 & 70 & 60 & 40 \\
8 & 11 & 13 & 40 & 10 & 40 \\
\hline
\end{tabular}

goal cup. Conventional programming and recording equipment were available through a plugboard, as required by the procedure.

\section{Pretraining}

The pretraining involved having the rats in groups of two break the photobeam at the end of each alley for one drop of water or for one $45 \cdot \mathrm{mg}$ Noyes pellet. The animals continued to obtain food or water by breaking the photobeams throughout a daily 3-h session. The apparatus had all doors opened during this phase so that the animals were free to run from the black alley to the white alley and vice versa, receiving food or water as they broke the appropriate photobeam. This pretraining phase continued for 8 days, during which time the animals received no food or water in their home cages. At the end of the 8 days of pretraining, each animal was placed on a $12 \mathrm{~g}$ of food and $12 \mathrm{cc}$ of water maintenance diet and the titration procedure was begun.

\section{Titration}

During this phase, each animal was run from the startbox and allowed to choose either water or food. The guillotine door dropped after he broke the photobeam at the end of either alley. Each animal ran 10 trials per day on a rotated basis. All rats were initially placed on a $12-\mathrm{g}$ and $12-\mathrm{cc}$ maintenance diet with the amount of food and water received in the alley being subtracted from this amount. After 4 or more days on the 12-and-12 condition, each $\mathbf{S}$ was placed on a new diet intended to produce equal choice of food and water. Within the restriction that the total diet had to sum to 24 (e.g., $13 \mathrm{~g}$ and $11 \mathrm{cc}, 15 \mathrm{~g}$ and $9 \mathrm{cc}$, etc.), values were successively chosen on the basis of each individual rat's past performance. Specifically, a $\mathbf{S}$ that consistently went to food on the original $12-\mathrm{g} / 12-\mathrm{cc}$ condition had the food increased and the water decreased for an ensuing series of tests. This process was reiterated until each rat displayed more nearly equal choice of food and water within a single day's session. This maintenance condition was then continued for the remaining experimental manipulations. this period, with the greatest weight loss being $-2.2 \mathrm{~g}$ and the greatest gain being $7.7 \mathrm{~g}$. The daily mean number of food responses made by a pair of rats during a $3-h$ session was $1,036.35$; the mean for water responses was 2,389.37.

The titration procedure extended over a period of more than 6 weeks, and eventually showed that rats may respond to both food and water within a series of 10 trials. In Table 1 , the values that equated food and water choices for each animal are shown. The percent water choices for 3 successive days at the end of titration are also provided in Table 1 to show the relative approximation to a $50 \%$ choice point for each $S$ and also to show the amount of day-to-day fluctuation that may be expected. ${ }^{1}$ No animal responded with precisely $50 \%$ water choices on each day. Each $S$ did, however, respond to both food and water daily.

The results obtained from varying the amount of food received when the feeding condition was manipulated and the amount of water received held constant are shown in Fig. 1. This figure shows each animal's performance over the first 9-day series, the second 9-day series, and the combined data. The heavy line in the combination of the two series indicates the overall mean. An analysis of variance on these data showed that the linear trend accounted for almost all of the variance produced by manipulation of the food condition, $F(1,4)=20.04, \quad p<.05$ (Edwards, 1963).

The effect of the three orders within each 9-day cycle of manipulation of the feeding condition
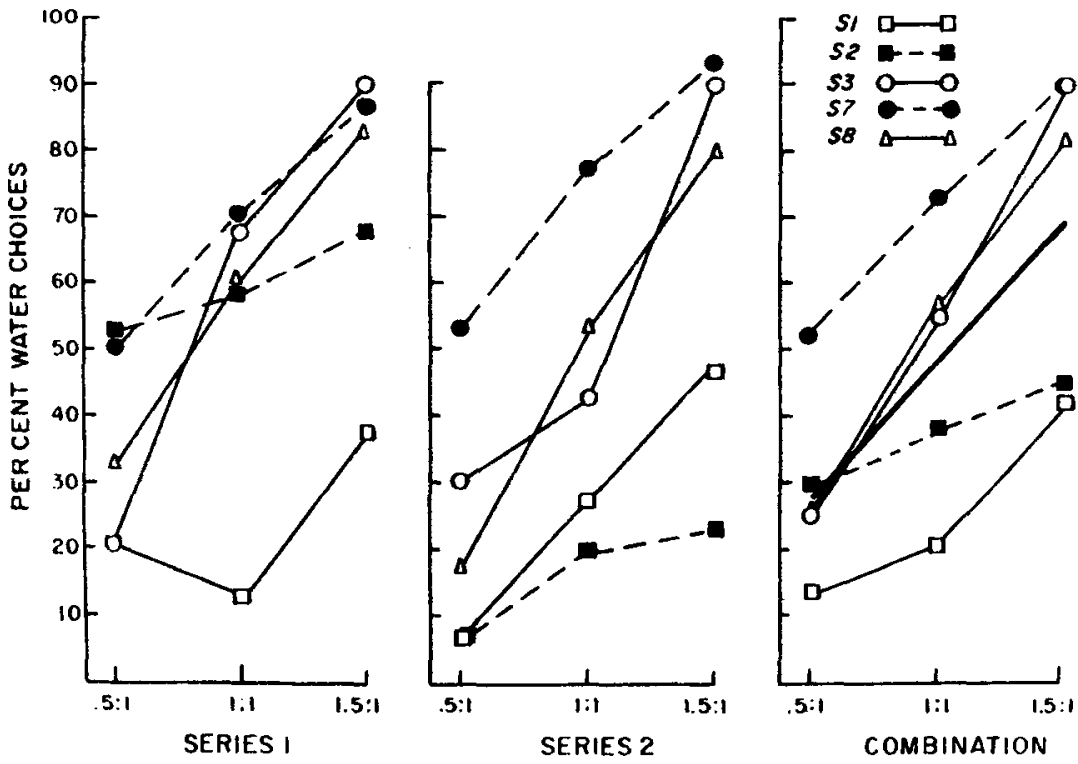

Fig. 1. Percent water choices for the first and second series and their combination for each $\mathbf{S}$ while the food condition was being varied. 
Table 2

Median Latency Measures (in Seconds) to Food With Feeding Condition Varied

Ratio: Amount of Food to Water

\begin{tabular}{llll}
$\mathrm{S}$ & $.5: 1$ & $1: 1$ & $1.5: 1$ \\
\hline 1 & 1.79 & 1.98 & 2.16 \\
2 & 2.16 & 2.17 & 2.18 \\
3 & 1.86 & 1.55 & 2.75 \\
7 & 2.29 & 2.40 & 2.64 \\
8 & 2.77 & 2.89 & 4.19 \\
\hline
\end{tabular}

is shown in Fig. 2. There seems to be little order effect in the experimental procedure.

The median latency of the median latencies from the three orders of the second 9-day series can be seen in Table 2. Apparatus failure prevented the collection of this data during the first series. These median latencies are only to the commodity that was varied, in this case food. An analysis of variance performed on these data shows the manipulation of the feeding condition to be significant, with $F(2,8)=5.50, p<.05$, and that the linear trend accounted for more of the variance, with $F(1,8)=9.30, p<.05$. The quadratic trend was not significant. Animals respond faster the less food they are given $23 \mathrm{~h}$ earlier, and this trend parallels the one found for percent water choices.

The percentage of each animal's weight on the days in both series when the 1.0:1.0 condition (the index weight) was in effect is shown in Table 3 for the $.5: 1.0$ and $1.5: 1.0$ conditions. There is a definite tendency for the animals to have the lowest percentage value of the index

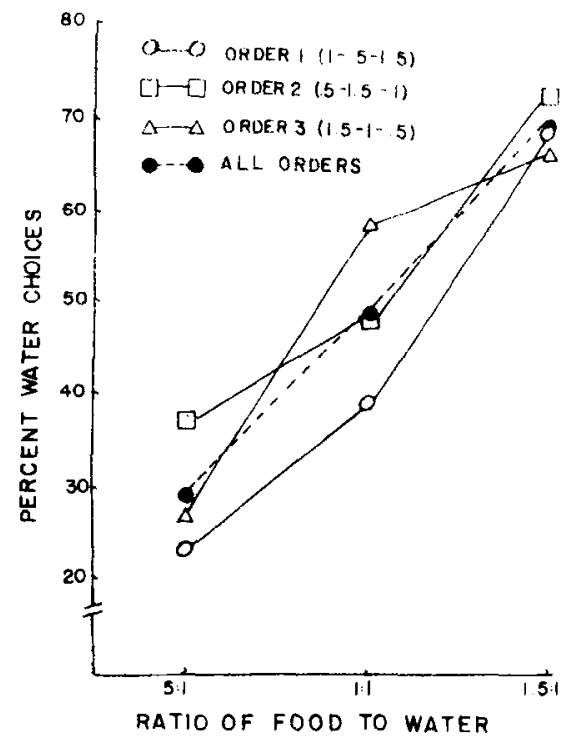

Fig. 2. Percent water choices for each order summed across all Ss while the food condition was varied. The function generated by summing across all orders is also shown. weight while under the $.5: 1.0$ condition and the largest value under the 1.5:1.0. An analysis of variance indicated a significant condition effect, $F(2,8)=6.69, p<.05$. The linear component did not reach significance.

\section{DISCUSSION}

The results indicate that the conditions of maintenance of food and water can be adjusted so as to make the resulting drives more nearly equal in strength. Presumably, there are any number of such combinations, the experimental determination of which should enable a more precise analysis of the way in which these drives accrue. This analysis, in turn, should permit more definitive research comparing hunger and thirst in other contexts.

For example, the early studies by Hull (1933) and Leeper (1935) have been interpreted as showing that hunger and thirst produce characteristic drive stimuli between which a rat can discriminate. However, no effort was made to equate the strength of hunger and thirst so that the discrimination could have been based on the intensity of a generalized drive state rather than upon more selective drive stimuli. In contrast, the present results provide a clear demonstration of the guiding role of drive stimuli. Similarly, comparative studies of hunger and thirst in relation to variables such as amount of reinforcement, delay of reinforcement, partial reinforcement, and the like presume a method of equating drive states in order to avoid confounding drive effects with incentive effects The present results show also that variations in the conditions of maintenance around the equated values as a frame of reference produce systematic changes in the relative strengths of hunger and thirst on a day-to-day basis. These effects were produced without substantial changes in total body weight or in the overall maintenance regime. Clearly, then, the rat is sensitive to momentary drive states related to his immediate history of eating or drinking. Finally, since the median latencies were found to vary with amount of food received $23 \mathrm{~h}$ earlier in much the same way as percent water choices varied, this measure could perhaps be used as an indicator of the strength of drive stimuli.

The procedure developed in this paper eliminates some of the methodological problems presented by Spence (1956). Varying the conditions of feeding and watering rather than the schedules of feeding and watering does not confound time in studies involving shifts in drive with the various experimental treatments. Also,
Table 3

Percent of the 1:1 Index Weight for Each $S$ During the Manipulation of Feeding Condition

\begin{tabular}{lrrr}
\multicolumn{4}{c}{ Feeding Condition } \\
\hline & \multicolumn{2}{c}{ Ratio: Amount of Food to Water } \\
\cline { 2 - 4 } $\mathbf{S}$ & $.5: 1$ & $1: 1$ & $1.5: 1$ \\
\hline 1 & 99.61 & 100.00 & 99.23 \\
2 & 99.74 & 100.00 & 100.23 \\
3 & 98.95 & 100.00 & 100.45 \\
7 & 98.87 & 100.00 & 101.20 \\
8 & 99.09 & 100.00 & 100.74 \\
\hline
\end{tabular}

it is possible to obtain rather regular data from individual Ss. Previous studies (Manning, 1956 ; Rethlingshafer, Eschenback, \& Stone, 1951) have shown only group functions in which attempts were made to map the functions combining hunger and thirst drives. The manipulations in the study cited here are regular enough to be considered somewhat comparable to the Skinnerian idea of schedules of reinforcement. The functions generated by each $\mathbf{S}$ are systematic across all orders. So drive might be redefined, for theoretical purposes, in terms of conditions rather than schedules of maintenance as has been done in the past. The construct might then be more amenable to experimentation.

Although more research is needed to determine the full utility of the described procedures, they do seem promising in providing a more analytic method for investigating the experimental construct of drive and drive stimuli.

\section{REFERENCES}

EDWARDS, A. L. Experimental design in psychological research. (Rev. ed.) New York: Holt, Rinehart \& Winston, 1963 FALLON, D. Effects of cyclic deprivation upon a consummatory behavior: The role of deprivation history. Journal of Comparative \& Physiological Psychology, $1965,60,283-287$.

HULL, C. L. Differential habituation to internal stimuli in the albino rat. Journal of Comparative Psychology, 1933, 16 255-273.

HULL, C. L. Principles of behavior. New York: Appleton-Century, 1943.

LEEPER, $R$. The role of motivation in learning: A study of the phenomenon of differential control of the utilization of habits. Journal of Genetic Psychology, $1935,46,3-40$

LOGAN, F. A., \& FERRARO, D. P. From free responding to discrete trials. In $W . N$. Schoenfeld (Ed.), The theory of reinforcement schedules, New York: Appleton-Century, 1970. Pp. 111-138.

MANNING, H. M. The effect of varying conditions of hunger and thirst on two responses learned to hunger or thirst alone. Journal of Comparative \& Physiological Psychology, 1956, 49, 249-253.

REID, L. S., \& FINGER, F. W. The rat's adjustment to 23-hour food deprivation cycles. Journal of Comparative \& 
Physiological Psychology, 1955, 48, Psychology, 1951, 41, 226-231.

110-113.

RETHLINGSHAFER, D. ESCHENBACK, A., \& STONE, J. T. Combined drives in learning. Journal of Experimental
SPENCE, $\mathrm{K}$. W. Behavior theory and

conditioning. New Haven: Yale University Press, 1956.

TOLMAN, E. C. Purposive behavior in animals and men. New York: Century, 1932.

NOTE

1. S 4 died before beginning any experimental procedures. 